\title{
HOMELAND / SOCIETAL VULNERABILITY AND SECURITY
}

decade after the end of the Cold war the world found itself in the face of
security challenges, risks, and threats that cannot be countered effectively by traditional security organizations. The security systems of many countries are in the process of transformation, while other countries create entirely new organizations.

To reflect the respective conceptual and organizational developments and to facilitate doctrinal, organizational, technological, and educational innovation, the Editorial Board of Information \& Security: An International Journal (I\&S) decided to prepare a special I\&S issue on vulnerabilities of modern societies and the search for higher levels of security.

Technical discussions of Homeland Security cannot occur in a void; they require both structural and cultural contexts if they are to be understood properly. Given this truth, the first two articles in this special issue of Information and Security deliberately seek to provide these contexts. Peter Faber's article provides the most "global" view of the topic, while Bengt Sundelius analyzes the societal dimensions of security today and provides a glimpse into proper organizational arrangements.

Christian Lanz then continues the general discussion by looking at homeland security from the viewpoint of a largely self-reliant neutral nation (Switzerland). Lionel Ponsard provides a Russian perspective on the subject, while Valeri Rachev presents the main problems in adapting security establishments of democratic countries to the challenges of spreading terrorism in a globalized world. He focuses on often neglected problems facing post-communist countries and the cultural impediments to the transformation of the security sector, as understood by Western analysts.

A research team from the Center for National Security and Defense Research in the Bulgarian Academy of Sciences assesses then the status and prospects ahead of Bulgaria's system for protection of population and critical infrastructure. The fundamental principles of the Concept for Civil Security of the Republic of Bulgaria have been formulated within the context of increasing integration of the security sector. 
The following two articles provide a comprehensive treatment of another very important subject - critical infrastructure protection. Eugene Nickolov examines the consequences of attacks on specific elements of the infrastructures, as well as the initiatives and problems that arise with their protection on national and international level. Finally, Klaus Niemeyer's article considers the crucial role of modeling and simulation in critical infrastructure protection and thoroughly presents his research and development efforts in this area.

This special issue provides also a comprehensive, up-to-date list with on-line resources on Homeland Security related journals, institutions, resource repositories, events, as well as some milestone publications.

The reader will not find answers to all related questions in this issue. We believe, though, that this I\&S volume will provide clear description of novel concepts, analysis of approaches and experience, and advanced modeling and analysis tools, that will be of service on the thorny path of creating systems for increased security in the Twenty First century that are both effective and preserve the values of democracy.

Information \& Security 